\title{
Geriatrics lymphedema: priority in therapeutic choices
}

\author{
S Michelini", M Cardone, A Failla, G Moneta, A Fiorentino, F Cappellino \\ From de Senectute: Age and Health Forum \\ Catanzaro, Italy. 5-7 December 2009
}

\section{Background}

The lymphedema is particularly common in the geriatric age. Physical treatment in primary and secondary lymphedema is basilar. It is more important to address the proper tailored treatment than it is to define the kind of patient $[1,2]$.

\section{Materials and methods}

The AA. observed 465 old patients suffering lymphedema, 36 primary, 239 'depending', 190 secondary.Three types of patients were identified in choosing the timing and intensity of each physical therapy :

1) able patients, who could do daily proper exercise (Group1).

2) less able who could perform average physical exercise (Group2).

3) bedridden patients (Group3).

In all patients limb circumferences were detected at the beginning after 10 sessions of treatment.

Treatment included: manual lymph drainage, bandaging, ultrasound and physical exercises. The bandage was packaged: multilayer anelastic in Group1; bielastic with a double superimposed anelastic layer in Group2; bielastic in single layer in Group3. Distinctions were not performed on rehabilitative protocol, according to the lymphedema nature (primary or secondary).

\section{Results}

After ten sessions of treatment the following was observed:

- Reduced average circumference of the limbs:

$46 \%$ in patients in group 1; $39 \%$ in patients of group 2; $18 \%$ in patients of group 3.
- Recovery of the function of the major joints of the affected limb:

average of 36 in group 1; average of 27 in group 2; average of 12 in group 3.

- Healing of trophic lesions:

$100 \%$ in group $1 ; 72 \%$ in group $2 ; 44 \%$ in group 3.

- Recovery of the functional autonomy in activities of daily living, determined by the ICF qualifiers:

a) Total in group 1

b) $82 \%$ in group 2

c) $42 \%$ in group 3

\section{Conclusions}

The study shows that the best results in the treatment of lymphoedema in a geriatric age, like in other ages, are achieved when the physical capacities of the patient are suitable for the performance of muscular exercises distributed throughout the day and when the cardiovascular compliance allows the application of techniques in absence of contraindications (heart failure, hypertension).

Published: 19 May 2010

\section{References}

1. Michelini S, et al: A new standardized classification tool which measures Lymphedema disability. The European Journal of Lymphology 2007, 17(50):11-5.

2. Lee BB, Piller N, Gloviczki P, Bergan J, Villavicencio L, Boccardo F, Michelini S, Drachten D, Andrade M, Lardo J, Campisi C, Mortimer P. Consensus on guidelines for diagnosis and treatment of primary lymphedema. International Angiology. 2009, 28:54.

doi:10.1186/1471-2318-10-S1-A104

Cite this article as: Michelini et al:: Geriatrics lymphedema: priority in therapeutic choices. BMC Geriatrics 2010 10(Suppl 1):A104.

San Giovanni Battista Hospital, Rome, Italy 